\title{
ECUADOR: LA CONTROVERSIA ENTRE ESTADO Y MERCADO. SIINTESIS DESDE LA HISTORIA ECONÓMICA
}

\author{
ECUADOR: THE CONTROVERSY BETWEEN THE STATE \\ AND THE MARKET. SUMMARY FROM ECONOMIC HISTORY
}

Paz y Miño Cepeda Juan J.'

\section{Resumen}

En el Ecuador del presente ha resurgido la controversia entre Estado y mercado. Pero hoy predomina la tesis según la cual el mercado libre y la empresa privada deberían ser los motores de la economía, ya que el Estado debe retirarse de esta esfera. La polémica es vieja. Sin embargo, descuida la perspectiva histórica que demuestra la necesaria acción del Estado en la economía y, además, que ese intervencionismo estatal ha sido fundamental para el desarrollo, la modernización y el progreso del Ecuador. Gracias a políticas estatales expresas a favor de la sociedad, se ha logrado mejorar las condiciones de vida y de trabajo.

\section{Palabras clave}

Estado, mercado, modelo empresarial, desarrollo

Clasificación JEL: B25, H75, O16.

\section{Abstract}

The old controversy between the State and the market in Ecuador has resurfaced. The idea that prevails today is that a free market and private enterprise should be the engine of the economy and the State must withdraw from this sphere. However, this idea neglects the historical perspective, which demonstrates the necessary action of the State in the economy and, moreover, states that interventionism has been fundamental for the development, modernization and progress of Ecuador. With tacit state policies in favour of society, it has been possible to improve living and working conditions.

\section{Keywords}

State, market, business model, development

JEL Classification: B25, H75, O16. 


\section{Introducción}

Con el gobierno de Lenín Moreno, quien empezó su período presidencial de cuatro años el 24 de mayo de 2017, ha revivido la controversia económica entre Estado y mercado. La discusión fue propia de las últimas décadas del siglo XX, cuando la ideología neoliberal, y con ella la idea de "retiro" y "achicamiento" del Estado, coparon la vida de los países latinoamericanos.

No se trata de una controversia teórica y abstracta, sino que responde a intereses sociales muy concretos: en el Ecuador actual, quienes abogan por el retiro y achicamiento del Estado son los dirigentes de las cámaras de la producción. Para sostener sus consignas suelen hacer referencia al gobierno de Rafael Correa (2007-2017), bajo el cual, supuestamente, el Estado se volvió "obeso" e intervencionista, afectando, así, la iniciativa privada y el mercado libre que, igualmente suponen, deberían ser los ejes "naturales" de conducción de la economía.

Sin embargo, si se confrontan las consignas empresariales con la historia económica del Ecuador, se encontrará que la afirmación del Estado nacional y de las posibilidades de progreso y de desarrollo están profundamente ligadas al fortalecimiento de las capacidades estatales y no a su debilitamiento.

En el siglo XIX el Estado ecuatoriano era "raquítico", pero hubo tres gobernantes que se preocuparon por fortalecerlo, a fin de lograr el progreso del país: Vicente Rocafuerte (1839-1845) (Mecum, 1983), Gabriel García Moreno (1860-1865 y 1869-1875) (Henderson, 2010), y Eloy Alfaro (1895-1901 y 1906-1911) (Paz y Miño, 2012). Sus esfuerzos por extender obras materiales como puentes, carreteras y el ferrocarril, así como para ampliar el sistema educativo con escuelas y colegios; además, para transformar la agricultura y favorecer el crecimiento de otras áreas productivas, requirieron de un acti- vo fomento e inversión estatales. Solo así fue posible cierta modernización nacional que no llegó nunca con el exclusivo esfuerzo privado de hacendados, terratenientes, agroexportadores, comerciantes y banqueros, que eran los grupos "empresariales" del país (Hurtado, 1977).

En el siglo XX fueron los gobiernos de la Revolución Juliana (1925-1931) los que sentaron las primeras bases para una activa intervención del Estado en la economía, que se consiguió al menos en el campo financiero con la creación del Banco Central del Ecuador. Los julianos también institucionalizaron las políticas sociales en el Estado con una temprana legislación sobre derechos laborales, seguridad social y atención médica y de salud, antes inexistentes; aparte de introducir, por primera vez, los impuestos directos, como el de rentas y uno sobre ganancias del capital (Paz y Miño, 2013).

Ese "estatismo" juliano, como lo calificaron, fue combatido a su época por las poderosas oligarquías de la Costa y la Sierra, que paralizaron su avance en las décadas posteriores.

Solo en las décadas de 1960 y 1970, cuando se implantó el modelo desarrollista, nuevamente el Estado pasó a ser el instrumento fundamental para la promoción económica, el progreso material y la modernización capitalista del Ecuador. Paradójicamente, esos avances quedaron en manos de dictaduras militares: la Junta Militar (19631966), el Nacionalismo Revolucionario (1972-1976) y el Consejo Supremo de Gobierno (1976-1979). El país progresó como nunca antes y bajo el espectacular auge petrolero de los años setenta se contó con recursos antes insospechados, que posibilitaron el sostenimiento de las políticas públicas, sistemáticamente resistidas y atacadas por las elites empresariales como "estatistas" 
y hasta "comunistas" (Acosta, 1998 y 2012; Pacheco, Sepúlveda et al., 1983).

El contraste llegó con los gobiernos democráticos a partir de 1979. Durante las décadas de 1980 y 1990, hasta principios del nuevo milenio, por sobre las distintas definiciones ideológico-políticas de los sucesivos presidentes, se edificó un solo modelo de economía que tuvo como ejes a la empresa privada y al mercado. Esto, una vez que se admitieron las consignas neoliberales en auge por toda Latinoamérica.

En tales condiciones, el Estado fue apartado de la economía y sus inversiones, servicios públicos y provisión de bienes para la sociedad sufrieron el peso del descuido, la mala atención, la corrupción, la falta de calidad y la sustancial pérdida de dinamia otrora observada con el modelo desarrollista.

El modelo empresarial de desarrollo de las décadas finales del siglo XX e inicios del XXI agravó las condiciones de vida y de trabajo en la sociedad ecuatoriana, favoreció la concentración de la riqueza que convirtió a Ecuador en uno de los países más inequitativos del mundo y permitió, sin duda, el amplio florecimiento de los negocios privados sobre dos bases adicionales: la flexibilización del derecho laboral y la primacía de los impuestos indirectos sobre los directos.

Hay que sumar a ello la desinstitucionalización del Estado y la crisis gubernamental que derivó en la sucesión de siete gobiernos (tres destituidos) y una dictadura nocturna durante una década: 1996-2006.

Bajo esas herencias, el comienzo del gobierno del presidente Rafael Correa (20072017) y la nueva Constitución de 2008 (aprobada por referendo) marcaron un nuevo ciclo político y económico para el Ecuador, que se inscribió en el marco de los gobiernos progresistas y de nueva izquierda en América Latina (Natanson, 2009; Mantilla, 2012).

El gobierno de Correa recuperó las capacidades del Estado, fortaleció la inversión pública, así como los servicios estatales, dando, con ello, una particular atención a las áreas de educación, medicina, salud, seguridad social, vivienda, economía social y solidaria. Quedó marcado un ciclo en el cual la recuperación del Estado continuó los procesos que, en su debido momento, ejecutaron los gobiernos julianos y los gobiernos desarrollistas (Paz y Miño, 2018).

El sucesor gobierno de Lenín Moreno volvió a alterar los procesos intervencionistas del Estado y definió otro momento histórico, pues retornó a las políticas económicas que confían en la inversión privada, el aliento al empresariado y la regulación "natural" del mercado libre. Han revivido los intereses y consignas de las cámaras de la producción, que han pasado a ser determinantes en la conducción económica gubernamental, lo cual incluye un giro internacional de retorno a las entidades multilaterales de crédito a cuya cabeza está el Fondo Monetario Internacional (FMI). Dicho organismo impuso las políticas económicas al Estado ecuatoriano en la época de vigencia del modelo empresarial de desarrollo.

Sobre la base de este resumen históri$\mathrm{co}$, es posible afirmar que es un mito indicar que el Estado ha sido algo así como "enemigo" de la empresa privada y del emprendimiento particular. Con el modelo desarrollista la empresa privada creció como nunca antes, gracias al Estado, un proceso comparable al que vivió el país con el gobierno del presidente Correa (Paz y Miño, 2016).

Como la historia económica del Ecuador poco se estudia y analiza a la hora de tomar políticas económicas en la coyuntura política y gubernamental, no se dimensiona el papel fundamental que desempeña el Estado en la región latinoamericana para conseguir un progreso y una modernización económica que, además, contribuyan a las condiciones de vida y de trabajo de la población. 
En Ecuador la participación del Estado no logra tomarse en cuenta para asumir como reto la implantación de un tipo de economía social comparable con las economías sociales de mercado existentes en Europa o en Canadá. La tendencia que se impone es a seguir y observar el tipo de economía norteamericana, aunque de ella se extrae la

\section{Metodología}

El texto se fundamenta en el análisis histórico. Toma como base los procesos del pasado para proyectar la reflexión desde el presente, en la línea teórica de la corriente

\section{Discusión}

Si se profundiza en la historia económica del Ecuador, se advertirá que el Estado, conducido por gobiernos que asumen utilizarlo como instrumento de progreso, ha desempeñado un papel decisivo en la modernización del país. Pero, además, solo gracias al Estado, bajo gobiernos de orientación social, se ha logrado difundir derechos laborales y colectivos, ampliar la atención ciudadana con servicios públicos, fortalecer la mejora en las condiciones de vida y de trabajo generales. Es un mito creer que solo la empresa privada ha sido capaz de generar empleo y bienestar para la población. Asimismo, es otro mito considerar al Estado un ente contrario a los intereses empresariales.

Desde la perspectiva económica, no solo pueden interesar los equilibrios de las distintas variables a través de las cuales se mide la estabilidad del sistema. En Ecuador es fundamental generar una conciencia distinta, que mida los logros económicos a través de la calidad de vida de la población mayoritaria, la atención estatal con servicios públicos y gratuitos, que impliquen la necesaria redistribución de la riqueza por medio de fuertes impuestos directos (rentas, patri- parte más conveniente a los intereses simplemente rentistas; esto es: el supuesto de una empresa privada absolutamente libre y de un mercado de competencia perfecta que, por cierto, no existe ni en los Estados Unidos, país en el cual se cuenta con fuertes capacidades estatales que no suelen ser estudiadas.

denominada historia inmediata. Se sustenta en investigación documental primaria y, a su vez, en la referencia a una bibliografía mínima sobre el tema.

monios, ganancias, herencias) y progresivos, con un alto impacto sobre las capas ricas.

Por otro lado, siguiendo las experiencias históricas de América Latina, el fortalecimiento de las capacidades estatales y su intervención directa en la economía, así como en el fomento del buen vivir social y ambiental, son parte de los desafíos contemporáneos para crear sociedades distintas a las heredadas. Sin embargo, esta no es una cuestión simplemente teórica, sino que implica que el manejo del Estado se subordine a los intereses más amplios de la población y se imponga sobre las elites empresariales que siguen resistiendo las posibilidades de acción estatal para la promoción social y nacional.

Si se consideran, con seriedad, los estudios alternativos sobre América Latina como los que difunde la Comisión Económica para América Latina y el Caribe (Cepal), igualmente se vería que hay una abundante reflexión científica institucional que advierte y remarca sobre las virtualidades del Estado como agente de desarrollo, progreso, modernización y buen vivir para las sociedades latinoamericanas (cf. www.cepal.org/es). 
Asimismo, en las investigaciones particulares de académicos pueden encontrarse fundamentos para remarcar el papel del Estado en las economías latinoamericanas $y$, sin duda, en Ecuador. Tomo, a manera de ejemplo, los trabajos de Hillel David Soifer, quien es profesor adjunto de ciencias políticas (política comparada) y se ha dedicado al desarrollo histórico de América Latina, actualizando el tema del papel del Estado en la región, redimensionando el concepto de "capacidad estatal".

Soifer (2015) discute y examina la construcción del Estado en la región durante los siglos XIX y XX. Para esto se apoya en múltiples fuentes y numerosos datos. Acude a la explicación histórica presentando las herencias coloniales, la independencia y el nacimiento de los nuevos Estados, el monopolio de la fuerza, la estabilidad y la inestabilidad. El eje de su estudio sigue siendo la "capacidad estatal" y en torno a ello explica

\section{Referencias}

Acosta, A. (1998). El Estado como solución. Quito, Ecuador: Friedrich Ebert Stiftung, ILDIS.

Corporación Editora Nacional (2012). Breve historia económica del Ecuador. Quito, Ecuador: Autor.

Henderson, P. (2010). Gabriel García Moreno y la formación de un Estado conservador en los Andes. Quito, Ecuador: Codecu, Gráficas Iberia.

Hurtado, O. (1977). El poder político en el Ecuador. Quito, Ecuador: Ediciones de la Universidad Católica.

Latin American Studies Association Stable. (2009). The Sources of Infrastructural Power: Evidence from Nineteenth-Century Chilean Education. Latin American Research Review, 44(2), 158-180. Published by: URL: http://www.jstor.org/stable/40783611 [Accessed: 23-02-2016 14:04 UTC]

Mantilla, S.; Mejía, S. (comp.). (2012). Rafael Correa. Balance de la revolución ciudadana. Quito, Ecuador: Editorial Planeta. los proyectos políticos, la primacía de lo urbano en lo regional y territorial nacional, la significación del "orden" y del "progreso", la incursión del liberalismo, el papel de la administración y de las instituciones estatales. Concentra particular atención en el desarrollo del sistema educativo; también en el régimen de los impuestos. Y discute la "construcción nacional" frente a la "construcción del Estado" (Soifer, 2009).

Aunque Soifer se concentra en cuatro países, Chile, Colombia, Perú y México (no hay referencias sobre Ecuador), su contribución al análisis y comprensión de la "capacidad estatal" en América Latina sirve para retomar el tema de la incursión del Estado en la economía y su papel en el desarrollo y la modernización. Así, invita a dejar de lado el prejuicio extendido por los políticos sobre el Estado como instrumento de acciones adversas frente a la misma economía y hasta "enemigo" de las actividades privadas.

Mecum, K. (1983). Vicente Rocafuerte, el prócer andante. Guayaquil, Ecuador: Banco Central del Ecuador.

Natanson, J. (2009). La nueva izquierda. Triunfos y derrotas de los gobiernos de Argentina, Brasil, Bolivia, Venezuela, Chile, Uruguay y Ecuador. Buenos Aires, Argentina: Editorial Sudamericana S. A., Debate.

Pacheco, L. (comp.); Sepúlveda, C. et. al. (1983). El Estado y la economía. Quito, Ecuador: Pontificia Universidad Católica del Ecuador.

Paz y Miño, J. (2012). Eloy Alfaro. Políticas económicas. Quito, Ecuador: Ministerio de Coordinación de la Política Económica. Recuperado en PDF: http://puce.the.pazymino.com/ELOY_ALFARO-Politicas_Economicas-Jun2012.pdf

Paz y Miño, J. (2013). La Revolución Juliana en Ecuador (1925-1931). Políticas económicas. Quito, Ecuador: Ministerio de Coordinación de la Política Económica. Recuperado en PDF: http://puce.the.pa- 
zymino.com/JPyM-REVOLUCION_JULIANAPoliticas_Economicas-2013.pdf

Paz y Miño, J. (2016). Historia y "capacidad estatal". El mito del Estado "obeso" y "enemigo" de la iniciativa privada. Boletín del THE. Quito, Ecuador: Pontificia Universidad Católica del Ecuador. Recuperado de http://www.historiaypresente.com/hyp/ wp-content/uploads/2016/11/historiacapacidad-estatal.pdf

Paz y Miño, J. (2018). Ecuador: los gobiernos julianos 1925-1931. La constitución de la iz- quierda política. Quito, Ecuador: Ediciones de la Pontificia Universidad Católica del Ecuador

Soifer, H. (2015). State Building in Latin America. New York, United States: Cambridge University Press.

\section{Referencia virtual}

Comisión Económica para América Latina y el Caribe www.cepal.org/es 